BAKTIMAS

Jurnal Pengabdian pada Masyarakat
Vol. 1, No. 3,

Oktober 2019
eISSN 2685-113x

pISSN 2685-0303

\title{
Pengembangan Teknologi Produksi Dan Pemasaran U Neulheu Di Desa Lingka Kuta Kecamatan Gandapura Kabupaten Bireuen Provinsi Aceh
}

\author{
Fatimah Zuhra, R Dedi Iman Kurnia, Safnina Sukma \\ Universitas Almuslim Bireuen \\ Email: zuhramatang@gmail.com \\ http://dx.doi.org/10.32672/btm.v1i3.1508
}

\begin{abstract}
Abstrak
Selain kaya akan wisata alam dan sejarah, kuliner Aceh juga beragam yang menggiurkan. Pasalnya, masakan Aceh dikenal lezat dengan citarasa khas dan rempah-rempah yang membuat ketagihan. Masakan Aceh merupakan berbagai kebudayaan seperti Arab, India, Siam, Spanyol, China, hingga Belanda. Namun, yang paling banyak mempengaruhi adalah masakan Arab dan India yang banyak menggunakan bumbu dan rempah-rempah. Salah satu bumbu masakan Aceh yang khas yaitu U Neulheu. Di kecamatan Gandapura terdapat beberapa pengusaha U Neulheu dengan jenis usaha home industri. Usaha U Neulheu masih sangat tradisional dalam proses pembuatannya, yaitu masih mengandalkan matahari dalam proses pengeringan $U$ Neulheu serta untuk menggongseng $U$ Neulheu juga masih menggunakan kuali biasa yang menghabiskan banyak waktu. Target Luaran dari kegiatan PKM Ini adalah meningkatnya produktifitas usaha $U$ Neulheu, manajemen usaha serta manajemen pemasaran yang baik, adanya peningkatan pengetahuan akan pemanfaatan teknologi informasi dalam pemasaran, memperluas jaringan pemasaran, dan merek dagang. Kegiatan PKM ini diharapkan dapat meningkatkan usaha U Neulheu mereka.
\end{abstract}

Kata kunci : U Neulheu, Bumbu Masak, Kuliner Aceh

\section{PENDAHULUAN}

Aceh adalah provinsi Indonesia yang terletak di paling barat. Aceh memiliki berbagai destinasi wisata yang sangat indah. Namun, selain kaya akan wisata alam dan sejarah, kuliner Aceh juga beragam yang menggiurkan. Pasalnya, masakan Aceh dikenal lezat dengan citarasa khas dan rempah-rempah yang membuat ketagihan. Masakan Aceh merupakan berbagai kebudayaan seperti Arab, India, Siam, Spanyol, China, hingga Belanda. Namun, yang paling banyak mempengaruhi adalah masakan Arab dan India yang banyak menggunakan bumbu dan rempah-rempah.

Salah satu bumbu masakan Aceh yang khas yaitu U Neulheu. U Neulheu adalah kelapa parut yang disangrai. Sebelum disangrai, kelapa parut dijemur terlebih dahulu sehingga kandungan minyak dalam kelapa menghilang. Setelah disangrai sampai menimbulkan warna kecoklatan dan beraroma khas, maka kelapa tersebut dihaluskan. Masyarakat Aceh biasanya menggunakan U Neulheu ini dalam masakan "Gulai Sie Itek" dan "Gulai Sie Manok" (masakan gulai bebek dan ayam). Kelapa gongseng giling 
BAKTIMAS

Jurnal Pengabdian pada Masyarakat
Vol. 1, No. 3,

Oktober 2019
eISSN 2685-113x

pISSN 2685-0303

biasanya dibuat dalam jumlah besar, kemudian disimpan dan dipergunakan sedikit demi sedikit. Kadar lemak pada kelapa gongseng giling yang terbuat dari kelapa tua sekitar 67-72\% dengan kadar air 1-2,9\% (Nilawati dkk., 2001; Fitriani, 2007).

Di desa Lingka Kuta Kecamatan Gandapura, Kabupaten Bireuen adalah salah satu tempat produksi U Neulheu diantaranya adalah usaha U Neulheu Bapak Muhammad. Usaha U Neulheu ini merupakan usaha mandiri yang telah ada sejak tahun 2008 dan memiliki \pm 20 pekerja lepas yang merupakan masyarakat sekitar. Produk utama dari usaha ini adalah U Neulheu, kelapa dipasok dari petani lokal yang secara tidak langsung ikut mendongkrak perekonomian petani kelapa. Setiap minggunya Bapak Muhammad dapat menghasilkan U Neulheu siap jual sebanyak $\pm 100 \mathrm{~kg}$ dengan harga jual dipasaran sekitar Rp. 20.000,- s/d Rp. 50.000,- perkilogramnya, seharusnya para pengusaha pliek $\mathrm{u}$ ini dapat memperoleh keuntungan perbulan \pm Rp. 8.000.000, perbulannya. Namun, minimnya modal membuat Bapak Muhammad masih menggunakan sistem produksi yang tradisional, sehingga hasil produksi mereka tidak maksimal. Apalagi ketika musim hujan, maka keuntungan dapat menjadi lebih kecil lagi bahkan tidak bisa beroperasi, hal ini karena usaha U Neulheu tersebut masih sangat tradisional dalam proses pembuatannya, yaitu masih mengandalkan matahari dalam proses pengeringan $U$ Neulheu serta untuk menggongseng $U$ Neulheu juga masih menggunakan kuali biasa yang menghabiskan banyak waktu.

Selain itu, proses pembuatan U Neulheu juga masih dilakukan secara tradisional, sehingga kualitasnya belum terstandarisasi. Dari proses pengeringan sampai ke tahap gongseng masih dilakukan dengan menggunakan peralatan rumah tangga sederhana. Begitu juga U Neulheu yang dijual juga masih belum dikemas dengan baik, masih menggunakan plastik biasa.

Dari sekian banyaknya inovasi yang sudah ada, bisa dikatakan proses pembuatan bumbu dapur masih tertinggal dalam hal teknologinya, apalagi jika usaha ini dapat menjadi penopang perekonomian masyarakat sekitar. Minimnya pengetahuan tentang manajemen usaha yang baik membuat usaha ini masih belum terorganisir dengan baik, sehingga banyak usaha sejenis yang dijalankan secara mandiri/perorangan.. Hal ini membuat para pengusaha U Neulheu tersebut tidak dapat mengembangkan usaha U Neulheu mereka. Padahal, harga jual U Neulheu dipasaran cukup tinggi namun terhambat dengan produksi yang minim.

\section{HASIL DAN PEMBAHASAN}

\section{Mesin Penggongseng U Neulheu}

Hasil yang telah dicapai pada pembuatan alat penggongseng kelapa parut dapat dilihat pada gambar dibawah ini: 
Fatimah Zuhra, R Dedi Iman Kurnia, Safnina Sukma

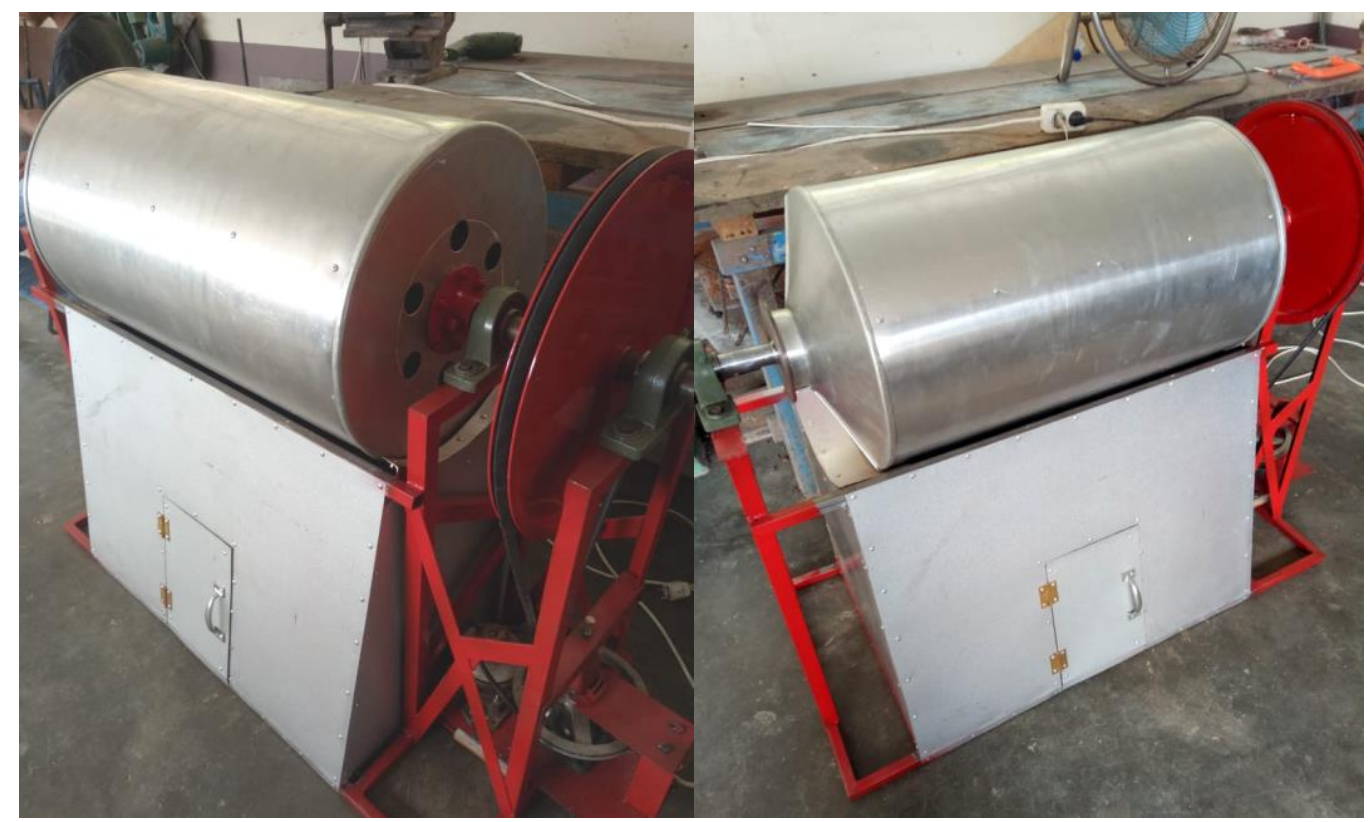

\section{Prinsip Kerja}

Alat penggongseng kelapa parut memiliki beberapa prinsip kerja diantaranya adalah sebagai berikut:

1. Alat penggongseng kelapa menggunakan sistem pemanas yaitu menggunakan kompor atau bara dari arang.

2. Proses pemanasan yang dilakukan oleh bara akan menghatarkan panas ke tabung sehingga proses penggongsengan terjadi

3. Motor listrik dengan putaran $1420 \mathrm{rpm}$ yang direduksi putaran oleh reducer sehingga dapat memutar mata pengaduk (mixing) dengan putaran 47,33 rpm .

4. Fungsi mixing dilakukan agar kelapa gonggseng tidak terdiam di kuali yang dapat mengakibatkan gosong.

5. Fungsi tombol navigasi dan lampu navigasi sebagai tempat menandakan bahwa elemen pemanas masih bekerja untuk menghasilkan panas $80^{\circ} \mathrm{C}$.

\section{Spesifikasi Alat}

Spesifikasi alat penggongseng kelapa dapat memberikan informasi yang berguna sebagai bahan pertimbangan untuk dijadikan acuan oleh konsumen. Adapun spesifikasi alat dapat dilihat pada tabel dibawah ini: 
BAKTIMAS

Jurnal Pengabdian pada Masyarakat
Vol. 1, No. 3,

Oktober 2019
eISSN 2685-113x

pISSN 2685-0303

\begin{tabular}{|c|l|c|}
\hline No & \multicolumn{1}{|c|}{ Spesifikasi } & Dimensi \\
\hline 1 & Berat total & \\
\hline 2 & Lebar & \\
\hline 3 & Panjang & \\
\hline 4 & Tinggi & \\
\hline 5 & Spesifikasi Tabung & \\
\hline 6 & Spesifikasi Motor Penggerak & \\
\hline 7 & Jenis Mata Pengaduk (Mixing) & \\
\hline 8 & Waktu Penggongsengan & \\
\hline
\end{tabular}

Dengan inovasi dari alat penggongseng $U$ Neulheu ini menjadikan proses produksi U Neulheu menjadi meningkat, baik itu dari segi efisiensi waktu maupun dari kuantitas dan kualitas produk yang dihasilkan.

\section{Pemasaran}

Untuk saat ini, pasar U Neulheu Pak Muhammad di desa Lingka Kuta Kecamatan Gandapura, Kabupaten Bireuen sangat berkembang dan banyak sekali peminatnya. Tetapi ada beberapa hal yang masih dilakukan dengan cara sederhana, seperti kemasan masih menggunakan plastik biasa yang diikat dengan karet, serta tidak ada label merek usaha.

Pada kegiatan Pengabdian Kepada Masyarakat (PKM) kali ini peneliti telah memberikan pelatihan kepada usaha U Neulheu Bapak Muhammad yakni pelatihan desain merek, pengemasan produk, manajemen usaha serta pelatihan pemasaran menggunakan teknologi informasi sehingga $U$ Neulheu yang dipasarkan akan lebih menarik serta terstandarisasi.

\section{KESIMPULAN}

1. Proses pembuatan kelapa gongseng dari kelapa yang telah diparut dilakukan dengan metode penggongsengan serta pemanas menggunakan api dan motor penggerak untuk mengaduk kelapa di dalam tabung.

2. Prinsip kerja dari alat gongseng kelapa ini terjadi didalam tabung yang di panas menggunakan bara atau api yang kemudian di aduk oleh mata pengaduk (mixing) dengan putaran $360^{\circ}$ yang ditransmisikan oleh gearbox dengan penggerak utama motor listrik.

3. Spesifikasi alat \pm memiliki panjang $=\mathrm{mm}$, lebar $=\mathrm{mm}$, dan tinggi $=\mathrm{mm}$ dan berat $\pm \mathrm{kg}$ dan bersifat portable

4. Hasil pengujian struktural dan fungsional yang telah dilakukan pada alat penggongseng kelapa ini dapat disimpulkan bahwa seluruh komponen bekerja sesuai dengan perencanaan. 
Fatimah Zuhra, R Dedi Iman Kurnia, Safnina Sukma

\section{DAFTAR PUSTAKA}

Badan Pusat Statistik Kabupaten Bireuen, 2016, Kabupaten Bireuen dalam angka 2016. Hasrin Lubis, Al Fathir, Abas, Rancang Bangun Alat Penggongseng Kelapa Untuk Pembuatan Bumbu Dapur Dengan Menggunakan Pemanas Listrik Temperatur 800c Dengan Kapasitas $3 \mathrm{Kg}$, 2016, Jurnal Polimesin (ISSN: 1693-5462), Volume 14, Nomor 1, Februari 2016, Politeknik Negeri Lhokseumawe.

Musarhan, Teknologi Tepat Guna Kelapa Gonseng Produk Gampong Cot Puuk, 2016, Politeknik Negeri Lhokseumawe

Kotler, Philip. 2001. Manajemen Pemasaran di Indonesia : Analisis, Perencanaan, Implementasi dan Pengendalian. Salemba Empat. Jakarta.

Sumarwan. U, 2015. Pemasaran Strategic: Perspektif Perlilaku Konsumen dan Marketing Plan. IPB Press 